\title{
Fauna parasitária e relação parasito-hospedeiro de tambaquis criados na região do Baixo São Francisco, nordeste do Brasil
}

[Parasitic fauna and parasite-host relationship of tambaqui reared in São Francisco river basin, Brazilian northeast]

\author{
R.Y. Fujimoto ${ }^{1,3}$, D.M.V. Hide1, P.E.G. Paixão ${ }^{1}$, H.A. Abe ${ }^{2}$, J.A.R. Dias ${ }^{2}$, N.C. Sousa ${ }^{2}$, \\ M.V.S. Couto ${ }^{2}$, R.V.B. Silva ${ }^{4}$, R.R. Madi ${ }^{1}$, M.V. Benavides ${ }^{3}$, M.M. Ishikawa ${ }^{3}$, \\ E.C. Chagas $^{3}$, C.L. Boijink ${ }^{3}$, M.H.G. Dompieri ${ }^{3}$, A.M.L. Pereira ${ }^{3}$, P.O. Maciel ${ }^{3}$ \\ ${ }^{1}$ Aluno de pós-graduação - Universidade Tiradentes - Aracaju, SE \\ ${ }^{2}$ Aluno de pós-graduação - Universidade Federal do Pará - Belém, PA \\ ${ }^{3}$ Empresa Brasileira de Pesquisa Agropecuária - Aracaju, SE \\ ${ }^{4}$ Instituto Federal de Sergipe - Aracaju, SE
}

R.Y. Fujimoto1,3

https://orcid.org/0000-0002-5039-4445 D.M.V. Hide ${ }^{1}$

https://orcid.org/0000-0002-3720-385 P.E.G. Paixão ${ }^{1}$ https://orcid.org/0000-0002-8949-4232 H.A. Abe2

https://orcid.org/0000-0002-5717-964 J.A.R. Dias 2

https://orcid.org/0000-0001-9751-0207 N.C. Sousa2

https://orcid.org/000-0002-7580-5650 M.V.S. Couto2

https://orcid.org/0000-0001-9235-0996 R.V.B. Silva4

https://orcid.org/0000-0002-6529-4324 R.R. Madi

https://orcid.org/0000-0002-1526-0687 M.V. Benavides 3

htps://orcid.org/0000-0002-0411-8175 M.M. Ishikawa3

https://orcid.org/0000-0003-4187-1948 E.C. Chagas 3

https://orcid.org/0000-0001-9170-9725 C.L. Boijink3

https://orcid.org/0000 000248757702 M.H.G. Dompieri3

https://orcid.org/0000-0001-7689-1602 A.M.L. Pereira3

https://orcid.org/0000-0002-4411-5278

https://orcid org/0000-0002-4151-6885

Este trabalho teve como objetivo avaliar a fauna parasitária de tambaquis na região do Baixo São FranciscoAL/SE-Brasil e correlacionar os índices de prevalência e intensidade média com fatores bióticos e abióticos. Foram coletados 252 espécimes para análise parasitológica de 10 pisciculturas. Os parasitos foram contabilizados, identificados, e determinaram-se os índices de prevalência e intensidade média, que foram correlacionados com fatores bióticos e abióticos. Dos peixes coletados, 65,5\% estavam parasitados por pelo menos um táxon. Foram encontrados 10 táxons: Monogeneas, Ichthyophthirius multifiliis, tricodinídeos, Piscinoodinium pillulare, Ichthyobodo sp., Dolops carvalhoi, Lernaea cyprinacea, Procamallanus (Spirocamallanus) inopinatus, Henneguya sp. e Myxobolus sp. As maiores prevalências foram encontradas para Monogeneas (49,2\%) e Myxobolus sp. (31,5\%). Correlações negativas entre prevalência e fatores bióticos (peso e comprimento) foram observadas para Monogeneas $\left(\mathrm{r}^{2}=-0,49 ; \mathrm{r}^{2}=-0,43\right)$, Myxobolus sp. $\left(\mathrm{r}^{2}=-0,46 ; \mathrm{r}^{2}=-\right.$ $0,39)$ e Henneguya sp. $\left(r^{2}=-0,41 ; r^{2}=-0,39\right)$. O fator abiótico temperatura apresentou correlação negativa com as prevalências de Lernaea cyprinacea $(\mathrm{r}=-0,39)$ e tricodinídeos $(\mathrm{r}=-0,33)$, enquanto a condutividade elétrica apresentou correlação positiva $(\mathrm{r}=0,40)$ com a prevalência de tricodinídeos. Conclui-se que a fauna parasitária dos tambaquis cultivados na região do Baixo São Francisco é diversificada e com a carga parasitária dependente da qualidade de água e do estágio de desenvolvimento dos peixes.

Palavras-chave: aquicultura, Colossoma macropomum, manejo, parasitos, sanidade

\section{ABSTRACT}

This study investigated the parasitic fauna of tambaquis reared in lower Sao Francisco region-Al/SE-Brazil correlating parasitic indices to abiotic and biotic factors. A total of 252 specimens of tambaqui were collected in ten fish farms for parasitological analysis. The parasites were counted, identified and the parasitological indices were determined and correlated to biotic and abiotic factors. Of all collected fish, 65,5\% were parasitized by at least one taxon. Ten taxa were found: Monogeneans, Ichthyophthirius multifiliis, trichodinids Piscinoodinium pillulare, Ichthyobodo sp, Dolops carvalhoi, Lernaea cyprinacea, Procamallanus (Spirocamallanus) inopinatus, Henneguya $\mathrm{sp}$. and Myxobolus sp. The higher prevalences were found to monogeneans (49.2\%) and Myxobolus sp. (31.5\%). Negative correlation of prevalence and biotic factor (weight and length) were observed to monogeneans $\left(r^{2}=-0.49, r^{2}=-0.43\right)$, Myxobolus $\mathrm{sp}\left(r^{2}=-0.46 ; r^{2}=-0.39\right)$ and Henneguya $\mathrm{sp}\left(r^{2}=-0.41 ; r^{2}=-0.39\right)$. Abiotic factor of temperature presented a negative correlation to prevalence of Lernaea cyprinacea and trichodinids $(r=-0.39$ e $r=-0.33$, respectively) and the electric conductivity presented positive correlation to trichodinids $(r=0.40)$. It was concluded that parasitic fauna of tambaquis cultured in Lower São Francisco region is diversified and the parasitic load dependent on water parameters and fish growth.

Keywords: aquaculture, Colossoma macropomum, health, management, parasites

Recebido em 16 de setembro de 2017

Aceito em 26 de março de 2018

E-mail: ryfujim@hotmail.com 


\section{INTRODUÇÃO}

A região do Baixo São Francisco, nordeste brasileiro, destaca-se pela potencialidade no cultivo de peixes, devido a sua abundância e qualidade de água com níveis adequados de oxigênio dissolvido, baixa amplitude térmica, solo adequado, localização geográfica privilegiada e instituições articuladas para incentivar as atividades aquícolas (Araújo e Pereira de Sá, 2008). Aliada a isso, há uma crescente demanda de peixes para o consumo humano, a qual tem contribuído para o impulso no desenvolvimento da piscicultura nessa região, com destaque para algumas espécies nativas brasileiras, dentre elas o tambaqui (Colossoma macropomum). O tambaqui é a segunda espécie mais produzida no Brasil, com produção de 111 mil toneladas em 2011, que representou 20,4\% da produção nacional, sendo esse valor maior que a produção de tambacu (Colossoma macropomum x Piaractus mesopotamicus), carpa (Cyprinus carpio) e pacu (Piaractus mesopotamicus) (Brasil, 2013).

O aumento do número de pisciculturas tanto no Baixo São Francisco quanto em todo o Brasil, associado à intensificação da produção, tem preocupado piscicultores quanto aos aspectos relacionados à sanidade, à sobrevivência e à qualidade dos peixes cultivados (Martins et al., 2004). Em sistemas intensivos, o limiar de equilíbrio entre os agentes patogênicos, o ambiente e o hospedeiro pode ser facilmente desestabilizado, ocasionando altas taxas de mortalidade decorrentes de surtos de doenças devido a um manejo inadequado que provoca estresse (Martins et al., 2004). Somado a isso, as pisciculturas não são acompanhadas por técnicos capacitados na identificação de doenças e na tomada de decisão das medidas profiláticas ou terapêuticas adequadas, o que aumenta as taxas de mortalidade, diminui o desempenho produtivo e aumenta os custos da produção (Assis e Freitas, 2012).

Altas infecções e mortalidades de tambaquis já foram relatadas em outras regiões, decorrentes de parasitos, como o acantocéfalo Neoechinorhyncus buttnerae (Malta et al., 2001), no estado do Amazonas, o dinoflagelado Piscinodinnium pillulare e o mixosporídeo Henneguya sp., no estado de Goiás (Sant'Ana et al., 2012), e o copépoda Perulernaea gamitanae, na Amazônia peruana (Delgado et al., 2011). Apesar da importância do tambaqui e da preocupação com a qualidade e sanidade do pescado na região do Baixo São Francisco, mais informações são necessárias sobre a fauna parasitária do tambaqui na região, assim como sua relação parasito-hospedeiro, sua proliferação e distribuição geográfica, a fim de permitir a elaboração de medidas mitigatórias e profiláticas pontuais ou coordenadas.

Assim, este trabalho teve como objetivo avaliar a fauna parasitária do tambaqui na região do Baixo São Francisco, nos estados de Alagoas e Sergipe, e correlacionar os índices de prevalência e intensidade média com os fatores bióticos e abióticos

\section{MATERIAL E MÉTODOS}

Foram amostradas ao acaso 10 propriedades, situadas nos municípios de Porto Real do Colégio $(n=3)$ e Igreja Nova $(n=3)$, no estado de Alagoas, e no município de Propriá $(n=4)$, no estado de Sergipe, as quais retratavam as características gerais das pisciculturas na região do Baixo São Francisco (Fig. 1).

Em cada propriedade, foram realizadas duas coletas ao longo de um ano, distribuídas entre junho e julho/2014 (chuva) e entre setembro/2014 e março/2015 (estiagem). Em cada coleta, os peixes foram capturados com rede de arrasto ou tarrafa e acondicionados em tonéis plásticos de 100 litros com água do respectivo viveiro e aeração constante, sendo, então, os indivíduos transportados até a unidade da Embrapa Tabuleiros Costeiros (Aracaju/SE) para realização das análises parasitológicas. No momento da captura dos peixes, ainda na piscicultura, foi realizado um exame macroscópico para avaliação de parasitos visíveis a olho nu na superfície corporal. Quando presentes, os parasitos foram coletados, fixados e conservados para identificação. No momento da coleta, também foram mensurados os parâmetros de qualidade de água, como: pH (Akrom $\left.\mathrm{Kr} 20{ }^{\circledR}\right)$, temperatura e níveis de oxigênio dissolvido (YSI 550A®), condutividade (YSI $30 ®)$ e transparência (utilizando-se disco de Secchi). 


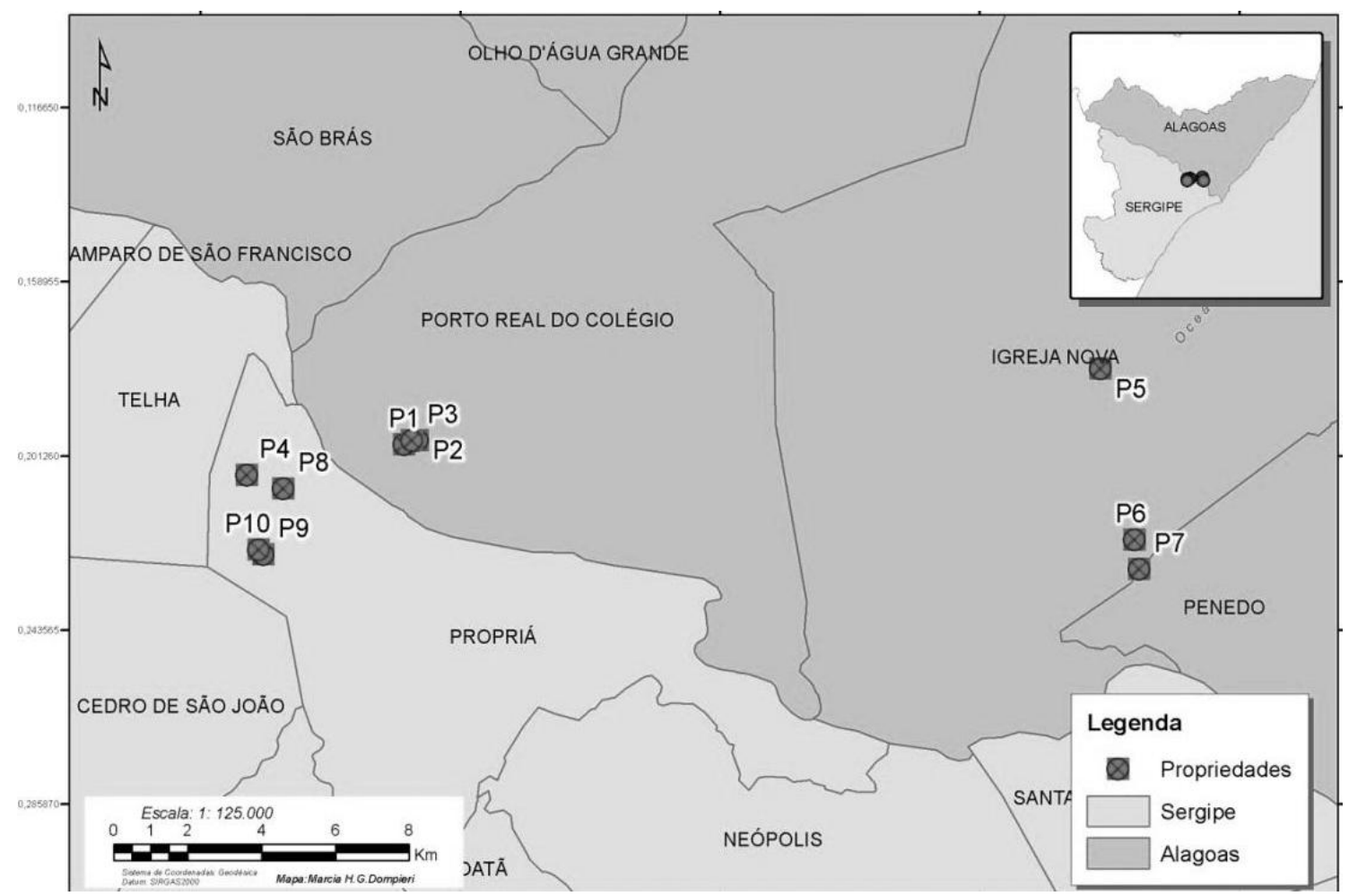

Figura 1. Localização das propriedades analisadas $(\mathrm{P})$ nos estados de Alagoas e Sergipe, na região do Baixo São Francisco.

No laboratório, todos os peixes foram previamente anestesiados (eugenol:álcool, 1:10 por aspersão nas brânquias) (Boijink et al., 2017), para realização de biometria, seguida de eutanásia por secção medular para posterior análise parasitológica. Todos os procedimentos com animais foram aprovados pelo Comitê de Ética ( $n^{\circ}$. 003/2014 -Ceua/UFGD). Em cada indivíduo, foram analisados: muco, brânquias, fígado, rim, cecos pilóricos, intestino, estômago, vesícula gasosa e fragmento do músculo da região dorsal. Os parasitos protozoários foram visualizados, fixados em lâmina e corados, segundo procedimentos de Eiras et al. (2006), para identificação até o menor nível taxonômico possível.

Os arcos branquiais foram removidos e examinados imediatamente em microscópio (Coleman N-120) e estereomicroscópio (Coleman NSZ-405); em seguida, foram imersos em água quente $\left(60^{\circ} \mathrm{C}\right)$ e fixados em formol $10 \%$. $\mathrm{O}$ trato digestório foi removido e analisado com auxílio de esteromicroscópio e microscópio, sendo o conteúdo fixado em AFA (álcool: formol: ácido acético). Os demais órgãos tiveram fragmentos analisados em preparados a fresco e foram examinados com auxílio de microscópio. A metodologia utilizada na coleta, fixação e preparação dos parasitos para identificação seguiu recomendações de Eiras et al. (2006). Posteriormente, eles foram identificados até o menor nível taxonômico possível, com auxílio de literatura específica (Thatcher, 2006; Cohen et al., 2013).

Após a quantificação dos parasitos em seus respectivos sítios, foram determinados os índices parasitológicos de acordo com Bush et al. (1997): intensidade média de infecção $\left(\mathrm{IM}=\mathrm{n}^{\circ}\right.$ total de parasitos $/ \mathrm{n}^{\circ}$ total de hospedeiros infectados $)$ e prevalência $\left(\mathrm{P}=\left(\mathrm{n}^{\mathrm{o}}\right.\right.$ total de hospedeiros infectados $/ \mathrm{n}^{\mathrm{o}}$ total de hospedeiros analisados) $x$ 100). Os protozoários e os mixosporídeos não foram quantificados, portanto não foi determinada a intensidade média de infecção. Foi realizada correlação de Spearman entre os fatores bióticos (peso e comprimento padrão $\mathrm{CP}$ ) e abióticos (parâmetros de qualidade de água) e os índices de prevalência e intensidade média de cada parasito, sendo considerada significativa quando $\mathrm{P}<0,05$. Para 
tanto, foi utilizado o critério de que somente prevalências maiores que $1 \%$ e intensidades médias maiores que 100 seriam utilizadas para essa análise. $\mathrm{O}$ teste $\mathrm{T}$ foi aplicado para analisar diferenças entre prevalência parasitária e períodos de coleta (estiagem e chuva). As análises foram realizadas com auxílio do software ®BioEstat 5.0.

\section{RESULTADOS}

Os valores médios dos parâmetros de água analisados durante o período de coleta foram: $\mathrm{pH}$ $7,6 \pm 0,6$; oxigênio dissolvido $5,1 \pm 2,1 \mathrm{mg} / \mathrm{L}$; temperatura $\quad 28,4 \pm 1,5^{\circ} \mathrm{C} ; \quad$ condutividade $808,8 \pm 597,8 \mu \mathrm{s} / \mathrm{cm}$; e transparência $18,5 \pm 8,9 \mathrm{~cm}$.

Não houve sazonalidade na incidência dos parasitos encontrados $(\mathrm{P}>0,05)$. No total de 252 peixes coletados (CP $21,8 \pm 7 \mathrm{~cm}$ e peso 438,0 $\pm 365,6 \mathrm{~g}), 165(65,5 \%)$ estavam parasitados por pelo menos um táxon. Foram identificados 10 táxons distintos, sendo: Monogeneas; Ichthyophthirius multifiliis (Fouquet, 1876), Trichodina sp., Piscinoodinium pillulare (Schäperclaus, 1954) Lom, 1981, Ichthyobodo sp. (Protozoa); Dolops carvalhoi Lemos de Castro, 1949, Lernaea cyprinacea Linnaeus, 1758 (Copepoda); Procamallanus (Spirocamallanus) inopinatus Travassos, Artigas e Pereira, 1928 (Nematoda); Henneguya sp. e Myxobolus sp. (Myxozoa) (Tab. 1).

Os Monogeneas e os Myxobolus sp. apresentaram as maiores prevalências $(49,2 \%$ e $31,5 \%$, respectivamente), enquanto Ichthyobodo sp., $P$. (S.) inopinatus e I. multifillis apresentaram os menores índices de prevalência $(0,8 \%, 0,8 \%$ e $0,4 \%$, respectivamente). Entre os metazoários, os Monogeneas também obtiveram a maior intensidade média de infestação $(222,9)$ (Tab. 1).

Tabela 1. Local de infecção, prevalência e intensidade média de infecção (IM) por parasito (ND= não determinado) em tambaquis (Colossoma macropomum) cultivados na região do Baixo São Francisco

\begin{tabular}{llcc}
\hline \multicolumn{1}{c}{ Parasito } & \multicolumn{1}{c}{ Local de infecção } & $\begin{array}{c}\text { Prevalência } \\
(\%)\end{array}$ & IM \\
\hline Monogeneas & Superfície corporal e brânquias & 49,2 & 222,9 \\
Myxobolus sp. & Todos os órgãos analisados & 31,5 & ND \\
Lernaea cyprinacea & Superfície corporal & 7,9 & 3,1 \\
Henneguya sp. & Brânquias & 4,8 & ND \\
Piscinoodinium pillulare & Brânquias & 3,2 & ND \\
Tricodinídeos & Superfície corporal e brânquias & 3,6 & ND \\
Dolops carvalhoi & Superfície corporal & 2,0 & 1,0 \\
Procamallanus (S.) inopinatus & Trato digestório & 0,8 & 1,5 \\
Ichthyobodo sp. & Superfície corporal e brânquias & 0,8 & ND \\
Ichthyophthirius multifillis & Superfície corporal & 0,4 & ND \\
\hline
\end{tabular}

Foram observadas correlações negativas entre prevalência, peso e comprimento dos peixes para os Monogeneas $\left(r^{2}=-0,49 ; r^{2}=-0,43\right)$, Myxobolus sp. $\left(\mathrm{r}^{2}=-0,46 ; \mathrm{r}^{2}=-0,39\right)$ e Henneguya sp. $\left(\mathrm{r}^{2}=-\right.$ 0,$\left.41 ; r^{2}=-0,39\right)$. Os fatores abióticos, como temperatura, apresentaram correlações negativas com as prevalências de Lernaea cyprinacea e tricodinídeos $\quad(\mathrm{r}=\quad-039$ e $\quad \mathrm{r}=\quad-0,33$, respectivamente), e a condutividade elétrica correlação positiva $(\mathrm{r}=0,40)$ com a prevalência de tricodinídeos. (Tab. 2). Para intensidade média, determinou-se uma correlação positiva com a temperatura da água para o parasito Monogenea $(r=0,36)$ (Tab. 2). 
Tabela 2. Valores do coeficiente de correlação de Spearman da prevalência e intensidade média de infecção em tambaquis (Colossoma macropomum) cultivados no Baixo São Francisco com fatores bióticos e abióticos $(*=\mathrm{P}<0,05)$

\begin{tabular}{lccccccc}
\hline \multicolumn{1}{c}{ Parasitos } & \multicolumn{9}{c}{ Fatores abióticos } & \multicolumn{3}{c}{ Fatores bióticos } \\
& $\mathrm{pH}$ & O.D. & T. & Condut. & Transp. & Peso & C.P. \\
\hline Myxobolus sp. & 0,04 & $-0,18$ & 0,26 & $-0,17$ & $-0,22$ & $-0,46^{*}$ & $-0,39^{*}$ \\
Tricodinídeos & $-0,21$ & 0,09 & $-0,33^{*}$ & $0,40^{*}$ & 0,10 & 0,20 & 0,12 \\
Henneguya sp. & $-0,10$ & $-0,18$ & 0,21 & $-0,06$ & 0,08 & $-0,41^{*}$ & $-0,39^{*}$ \\
Piscinoodinium pillulare & $-0,09$ & $-0,15$ & 0,003 & $-0,31$ & 0,14 & $-0,13$ & $-0,09$ \\
Monogenea & 0,13 & $-0,27$ & 0,27 & $-0,29$ & $-0,09$ & $-0,49^{*}$ & $-0,43^{*}$ \\
Dolops carvalhoi & $-0,13$ & $-0,13$ & $-0,18$ & 0,21 & 0,10 & 0,28 & 0,23 \\
Lernaea cyprinacea & 0,08 & $-0,02$ & $-0,39^{*}$ & $-0,05$ & 0,12 & $-0,20$ & $-0,28$ \\
Parasitos & & & & Intensidade média & & \\
Monogenea & 0,03 & $-0,26$ & $0,36^{*}$ & $-0,24$ & $-0,14$ & $-0,26$ & $-0,20$ \\
\hline
\end{tabular}

O.D.: oxigênio dissolvido; T.: temperatura; Condut.: condutividade elétrica; Transp.: transparência; e C.P.: comprimento padrão.

\section{DISCUSSÃO}

A fauna parasitária do tambaqui é constituída de 20 táxons, assim descritos: cinco espécies de Monogeneas (Anacanthorus spathulatus, A. penilabiatus, Notozotheciun janauachensis, Linguadactyloides brinkmanni e Mymarothecium boegeri); um Digenea da família Paramphistomidae; cinco nematoides (Spirocamallanus inopinatus, Spirocamallanus spp., Chabaudinema americana, Cucullanus colossomi e Procamallanus sp.); três Branchiuras (Dolops carvalhoi, Argulus chicomendesi e A. multicolor); dois Copépodas (Gamidactylus jaraquensis e Perulernaea gamitanae); dois mixosporídeos (Henneguya piaractus e Myxobolus colossomatis); e os protozoários Piscinoodinium pillulare e Ichthyophthirius multifiliis (Eiras et al., 2010). Na região do Baixo São Francisco, a fauna parasitária do tambaqui apresentou 10 táxons distintos, podendo, então, ser considerada uma fauna diversa, com um maior número de táxons quando comparada com estudos da região Norte, como nos estados do Amazonas ( $\mathrm{n}=9$ táxons identificados) (Fischer et al., 2003), Amapá (n= 5) (Santos et al., 2013) e Roraima (n= 7) (Godoi et al., 2012).
As maiores prevalências encontradas foram para os parasitos Monogeneas e Myxobolus sp. A infecção por Monogeneas corrobora os registros em tambaquis em que altas prevalências foram encontradas (95\%) em tambaquis cultivados na região Norte, especificamente no estado do Amapá (Santos et al., 2013). Já o protozoário Myxobolus sp. foi encontrado parasitando o tecido sanguíneo de tambaquis, órgãos internos e brânquias, assim como já registrado para $C$. macropomum (Martins et al., 1999; Maciel et al., 2011).

No presente estudo, apesar da baixa prevalência (7,9\%) e intensidade média ( 3,1 parasitos/peixe) observada para a $L$. cyprinacea, esse registro deve ser considerado relevante devido à possibilidade de ocorrência de surtos epizoóticos causados por lerneídeos. Na Amazônia peruana, a infestação pelo lerneídeo Perulernaea gamitanae atingiu $100 \%$ de prevalência, intensidade média de 268,8 parasitos por peixe e mortalidade total dos peixes cultivados (Delgado et al., 2011). Na Amazônia brasileira, o mesmo parasito foi registrado em tambaquis e nos híbridos tambatinga e tambacu (Tavares-Dias et al., 2011). Os autores registraram que o crustáceo $P$. gamitanae ocorre principalmente na língua e na boca dos hospedeiros, mas também 
nos filamentos e na cartilagem dos arcos branquiais. Nesse sentido, os lerneídeos são parasitos importantes a serem considerados nos planos coordenados de profilaxia nos peixes da região Nordeste do Brasil.

Outro fato relevante foi a ausência de acantocéfalos Neoechinorhynchus buttnerae nos peixes da região do Baixo São Francisco. Essa espécie vem provocando prejuízos sanitários e econômicos em cultivos de tambaquis na região Norte (Malta et al., 2001; Chagas et al., 2015). Assim, faz-se necessário um maior controle sanitário visando evitar a introdução desse patógeno na região do Baixo São Francisco, ocasionada por comercialização e transporte de alevinos, reprodutores e hospedeiros intermediários contaminados (ex.: copépodos zooplanctônicos).

Nas diferentes regiões do Brasil, a diversidade da fauna parasitária pode ser influenciada diretamente pelos fatores abióticos e bióticos, assim como pelo manejo, pelas instalações das pisciculturas, pelo ciclo de vida do parasito e pelo habitat do peixe. No presente trabalho, o fator biótico de baixo peso e comprimento favorece a infestação parasitária por Monogeneas, Myxobolus sp. e Henneguya sp., fato que pode estar associado à idade dos peixes, visto que indivíduos jovens são mais suscetíveis a doenças e parasitoses devido ao sistema imunológico em desenvolvimento (Faria et al., 2013).

Com relação aos fatores abióticos, tanto o desenvolvimento do tambaqui quanto o ciclo de vida parasitário são influenciados diretamente pela pluviosidade regional com grandes diferenças entre as épocas do ano (Lucas e Baras, 2001), porém, na região do Baixo São Francisco, não foram constatadas diferenças significativas entre a fauna parasitária dos tambaquis nas diferentes épocas de chuva e de estiagem. Isso pode estar relacionado a uma menor quantidade de chuvas regionais, aos tipos de estruturas de cultivo e ao confinamento dos peixes nos viveiros, diminuindo, assim, a influência dessas variações climáticas e os impactos entre as estações.

A temperatura permaneceu dentro dos valores recomendados para a criação do tambaqui, ideal para o bom desempenho zootécnico (Cavero et al., 2009), refletindo em uma correlação negativa entre a temperatura e os parasitos Trichodina sp. e L. cyprinacea. A baixa infestação desses parasitos na região decorre provavelmente da manutenção da alta temperatura no decorrer do ano. Baixas temperaturas favorecem a infestação desses parasitos devido ao estresse provocado nos peixes (Baldisserotto, 2002), que diminui a resposta imune.

Porém, observa-se o contrário para a intensidade média de infestação por Monogeneas, em que foi constatada correlação positiva com a temperatura. Tal fato pode estar associado à reprodução dos Monogeneas, que é favorecida pelo aumento da temperatura (Turgut, 2011).

A condutividade elétrica atingiu valores elevados, que podem ser decorrentes do manejo de fertilização dos viveiros com adubos químicos ou orgânicos (Queiroz, 2003). Ao se analisar conjuntamente com a transparência da água, nota-se que esta se manteve relativamente baixa, indicando uma alta concentração de fitoplâncton na água acima dos níveis indicados para piscicultura, o que sugere um manejo inadequado do preparo do viveiro. E, apesar da baixa infestação por tricodinídeos, a adubação pode estar favorecendo a infestação, pois, quando realizada de forma errônea, ocasiona excesso de matéria orgânica, aumento de condutividade com consequente aumento de fitoplâncton e piora da qualidade da água, condição esta que favorece a reprodução do parasito (Pavanelli et al., 1998) e que se refletiu na correlação positiva entre parasito e condutividade elétrica encontrada no presente estudo.

A elevação da condutividade elétrica da água dos viveiros também poderia ser decorrente de aplicações de sal pelos produtores, pois é um manejo frequentemente utilizado na atividade piscícola, porém sua utilização na região necessita de avaliações mais detalhadas para determinar se a frequência de utilização do sal na região seria suficiente para causar a alteração do parâmetro estudado. A prática de adição de sal, no entanto, é comum para a redução do estresse dos animais e o controle de alguns parasitos, como a L. cyprinacea, como constatado por Idris e Amba (2011), o que ocasionaria o efeito inverso do observado no presente trabalho. 
Nota-se, assim, que a maioria dos fatores associados ao risco de parasitismo tem relação direta com o crescimento dos peixes e os parâmetros de qualidade da água. O desequilíbrio de tais variáveis e o desconhecimento das relações entre parasito-hospedeiro-ambiente podem desencadear situações de estresse, diminuindo a resposta imune e tornando os peixes mais susceptíveis ao parasitismo (Santos et al., 2013). Além disso, a capacidade de suporte do ambiente dos viveiros deve ser respeitada, pois a piora na qualidade de água e/ou a redução no crescimento e o aumento do contato entre os peixes favorecem a disseminação dos parasitos (Baldwin, 2010). Dessa forma, boas práticas de manejo específicas são importantes para a profilaxia pontual para a região do Baixo São Francisco e, com base nessas informações, pode-se construir um cenário de prevenção coordenado para impedir a introdução de novos agentes patogênicos e, consequentemente, de surtos parasitários, contribuindo, assim, para o desenvolvimento sustentável da atividade na região.

\section{CONCLUSÃO}

A fauna parasitária dos tambaquis da região do Baixo São Francisco se apresenta mais diversificada que em outros estados do Brasil. A falta de controle da qualidade da água dos viveiros afeta negativamente a sanidade dos cultivos, tornando necessária a tecnificação da produção e a qualificação da mão de obra, para que sejam implementados procedimentos de manejo profilático e controle de qualidade da água, principalmente na fase inicial da criação.

\section{AGRADECIMENTOS}

Os autores agradecem ao Conselho Nacional de Desenvolvimento Científico e Tecnológico, pelo suporte financeiro para Rodrigo Yudi Fujimoto (305195/2016-6).

\section{REFERÊNCIAS}

ARAÚJO, J.S.; PEREIRA DE SÁ, M.F. Sustentabilidade da piscicultura no baixo São Francisco alagoano: condicionantes socioeconômicos. Ambien. Soc., v.11, p.405-424, 2008.
ASSIS, M.C.; FREITAS R.R. Analise das praticas de biossegurança no cultivo de tilápias (Oreochromis niloticus) em região estuarina no sudeste do Brasil. Rev. Gestão Costeira Integr., v.12, p.559-568, 2012.

BALDISSEROTTO, B. Fisiologia de peixes aplicada à piscicultura. Santa Maria: UFSM, 2002. 350p.

BALDWIN, L. The effects of stocking density on fish welfare. Plym. Stud. Sci., v.4, p.372-383, 2010.

BOIJINK, C.L.; MACIEL, P.O.; TAVARESDIAS, M. et al. Anesthesia by sprinkling method in the gills of tambaqui Colossoma macropomum does not influence intensity and morphology of monogeneans. Braz. J. Biol., v.77, p.367-371, 2017.

QUEIROZ, J.D. Boas práticas de manejo para a produção de peixes em tanques-rede. Jaguariúna, SP: Embrapa, 2003. 10p. (Circular Técnica, 26).

BRASIL. Ministério da Pesca e Aquicultura. Boletim estatístico de pesca e aquicultura do Brasil 2011. Brasília: MPA, 2013. 129p.

BUSH, A.O.; LAFFERTY, K.D.; LOTZ, J.M.; SHOSTAK, AW. Parasitology meets ecology on its own terms: Margolis et al. revisited. $J$. Parasitol., v.83, p.575-583, 1997.

CAVERO, B.A.S.; RUBIM, M.A.L.; PEREIRA, T.M. Criação comercial do tambaqui Colossoma macropomum (Cuvier, 1818). In: TAVARESDIAS, M. Manejo e sanidade de peixes em cultivo. Amapá: Embrapa, 2009. p.33-46.

CHAGAS, E.C.; MACIEL, P.O.; AQUINOPEREIRA, S.L. Infecções por acantocéfalos: um problema para a produção de peixes. In: TAVARES-DIAS, M.; MARIANO, W.S. Aquicultura no Brasil: novas perspectivas. São Carlos: Pedro \& João, 2015. p.305-328.

COHEN, S.C.; JUSTO, M.C.N.; KOHN, A. South American monogenoidea parasites of fishes, amphibians and reptiles. Rio de Janeiro: Oficina de Livros, 2013.

DELGADO, P.Q.; DELGADO, J.P.M.; ARENAS, J.V.; ORBE, R.I. Massive infestation by Perulernaea gamitanae (Crustacea: Cyclopoida: Lernaidae) in juvenile gamitana, cultured in the Peruvian Amazon. Vet. Méx., v.42, p.59-64, 2011. 
EIRAS, J.C.; TAKEMOTO, R.M.; PAVANELLI, G.C. Métodos de estudo e técnicas laboratoriais em parasitologia de peixes. 2.ed. Maringá: EDUEM, 2006.

EIRAS, J.C.; TAKEMOTO, R.M.; PAVANELLI, G.C. Diversidade dos parasitos de peixes de água doce do Brasil. Maringá: Clichetec, 2010.

FARIA, R.H.S.; MORAIS, M.; SORANNA, M.R.G.S.; SALLUM, W.B. Manual de criação de peixes em viveiros. Brasília: CODEVASF, 2013. 136p.

FISCHER, C.; MALTA, J.C.O.; VARELLA, A.M.B. A fauna de parasitas do tambaqui, Colossoma macropomum (Curvier, 1818) (Characiformes: Characidae) do médio Rio Solimões, estado do Amazonas (AM) e do baixo Rio Amazonas, estado do Pará (PA), e seu potencial como indicadores biológicos. Acta Amaz., v.33, p.651-662, 2003.

GODOI, M.M.I.M.; ENGRACIA, V.; LIZAMA, M.L.A.P.; TAKEMOTO, R.M. Parasite-host relationship between the tambaqui (Colossoma macropomum Curvier 1818) and ectoparasites, collected from fish farms in the City of Rolim de Moura, State of Rondônia, Western Amazon, Brazil. Acta Amaz., v.42, p.515-524, 2012.

IDRIS, H.B.; AMBA, M.A. A note on Lernaea cyprinacea parasitizing the cultured marble goby Oxyeleotris marmorata and their control with salinity modification. Adv. Environ. Biol., v.5, p.817-820, 2011.

LUCAS, M.; BARAS, E. Migration of freshwater fishes. Ames: Blackwell Science, 2001. 14p.

MACIEL, P.O.; AFFONSO, E.G.; BOIJINK, C.L.; TAVARES-DIAS, M.; INOUE, L. Myxobolus sp. (Myxozoa) in the circulating blood of Colossoma macropomum (Osteichthyes, Characidae). Rev. Bras. Parasitol., Vet., v.20, p.82-84, 2011.
MALTA J.C.O.; GOMES, A.L.S.; ANDRADE, S.M.S. et al. Infestações maciças por acantocéfalos, Neoechinorhynchus buttnerae Golvan, 1956, (Eoacantocephala: Neoechinorhynchidae) em tambaquis jovens, Colossoma macropomum (Curvier, 1818) cultivados na Amazônia Central. Acta Amaz., v.31, p.133-143, 2001.

MARTINS, M.L.; SOUZA, V.N.; MORAES, J.R.E. et al. Comparative evaluation of the susceptibility of cultivated fishes to the natural infection with myxosporean parasites and tissue changes in the host. Rev. Bras. Biol., v.59, p.263269, 1999.

MARTINS, M.L.; RANZANI-PAIVA, MJT; TAKEMOTO, RM, Manejo sanitário na Piscicultura p. 323-332, 2004.

PAVANELLI, G.C.; EIRAS, J.C.; TAKEMOTO, R.M. Doenças de peixes: profilaxia, diagnostico e tratamento. Maringá: EDUEM, 1998.

SANT'ANA, F.J.F.; OLIVEIRA, S.L.; RABELO, R.E. et al. Surtos de infecção por Piscinoodinium pillulare e Henneguya spp. Em pacus (Piaractus mesopotamicus) criados intensivamente no Sudoeste de Goiás. Pesqui. Vet. Bras., v.32, p.121-125, 2012.

SANTOS, E.F.; TAVARES-DIAS, M.; PINHEIRO D.A. et al. Fauna parasitaria de tambaqui Colossoma macropomum (Characidae) cultivado em tanque-rede no estado do Amapá, Amazônia Oriental. Acta Amaz., v.43, p.105-112, 2013.

TAVARES-DIAS, M.; NEVES, L.R.; SANTOS, E.F. et al. Perulernaea gamitanae (Copepoda: Lernaeidae) parasitizing tambaqui (Colossoma macropomum) (Characidae) and the hybrids tambacu and tambatinga, cultured in northern Brazil. Arq. Bras. Med. Vet. Zootec., v.63, p.988995, 2011.

THATCHER V.E. Amazon fish parasites. 2.ed. Sofia-Moskow: Pensoft Publisher, 2006.

TURGUT, E. Influence of temperature and parasite intensity on egg production and hatching of the monogenean Dactylogirus extensus. Isr. J. Aquacult., v.64, 5p., 2011. 